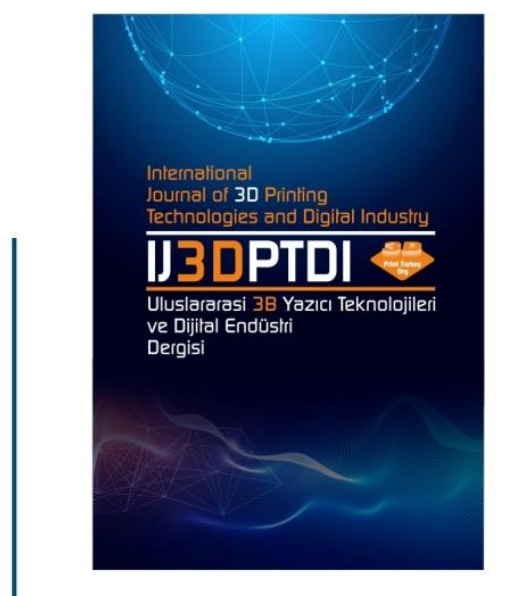

ULUSLARARASI 3B YAZICI TEKNOLOJILERI

VE DIJITAL ENDÜSTRI DERGISI

INTERNATIONAL JQURNAL QF 30 PRINTING TECHNOLOGIES AND DIGITAL INDUSTRY

I55N:2602-3350 [Online]

URL: https://dergipark.org.tr/ij3dptdi

\title{
EFFECT OF ORIENTATION DISTANCE ON TEMPERATURE INDUCED PROBLEMS IN MULTI-PART MANUFACTURING BY SELECTIVE LASER MELTING
}

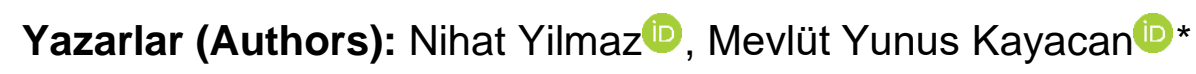

Bu makaleye şu şekilde atıfta bulunabilirsiniz (To cite to this article): Yılmaz N., Kayacan M.Y., "Effect of Orientation Distance on Temperature Induced Problems in MultiPart Manufacturing by Selective Laser Melting" Int. J. of 3D Printing Tech. Dig. Ind., 5(1): 43-55, (2021). 


\title{
Effect of Orientation Distance on Temperature Induced Problems in Multi- Part Manufacturing By Selective Laser Melting
}

\author{
Nihat Yilmaz ${ }^{\text {iD }}$, Mevlüt Yunus Kayacan ${ }^{\text {a }}$ iD * \\ aspartaUniversity of Applied Sciences, Technology Faculty, Mechanical Engineering, TURKEY \\ *Sorumlu Yazar: mevlutkayacan@isparta.edu.tr
}

(Received: 05.03.2021; Revised: 14.04.2021; Accepted: 17.04.2021)

\begin{abstract}
Selective Laser Melting (SLM) methods are widely used to manufacture metal parts for functional use in mainly automotive, aerospace and medical industries. Besides many advantages of SLM, manufacturing takes long times and need many costs. In this study, nine samples were manufactured at the same time to set a scenario of multiple samples manufacturing and providing highly productive conditions. Some manufacturing problems such as internal stresses and dimensional distortions occurred during manufacturing. These problems were the result of heterogeneous temperature gradients and geometrical properties. Finite Element Analysis (FEA) studies were carried out by "Netfabb Ultimate Simulation LT 2019". Temperature changes were observed, and relations among these temperature changes, residual stresses, as well as dimensional distortions were evaluated. As a result, the orientation distance of samples was an important parameter due to residual stress and displacement. Unsuitable positioning distance between samples caused high dimensional distortion, macro cracks and residual stress. The plastic strain equation was correlated according to the results of the analysis with 7\% difference (regression) to define the optimum distance between Ti6Al4V parts.
\end{abstract}

Keywords: Powder bed fusion, SLM, additive manufacturing, part orientation, residual stress

\section{INTRODUCTION}

Additive manufacturing ( $\mathrm{AM}$ ) processes differ in terms of the working principle, the method of melting or depositing layers to form parts, as well as in terms of the materials used [1]. Metal Powder Bed Fusion (PBF) is one of the most important AM methods, preferably using laser or electron beams to fuse metal powders, for the production of ready-to-use industrial parts from CAD data [2]. In a Powder Bed Fusion (PBF) system, a thin layer of metal powder is laid on the bench platform, and a focused laser beam is used to selectively melt the layer of a powder bed. Several layers are laid one after the other to form the component according to the 3D design, and this process continues until the part is complete [3]. Laser-based PBF (L-PBF) processes can also produce complex-shaped, lightened, functional graded or customized metal parts for highly demanding applications in automotive, military, aeronautics and medical industries. Laser-powder bed fusion (L-PBF) additive manufacturing involves complex physical processes such as beam absorptance, heat transfer, molten metal flow, phase transformation, thermal stress and distortion. All these factors influence the final part quality and non-failure manufacturing [4].

Each layer of powder deposited on the tray interacts with the laser beam before being melted onto the substrate. The melted particles form a molten pool on the surface of the rapidly growing layer, and the solidification of the molten region forms the structure. When the laser beam moves forward, the critical temperature gradient provides a strong convective liquid metal flow due to the Marangoni effect and facilitates convective heat transfer within the molten pool. The solidified material is exposed to multiple heating and cooling cycles as layers of new powders are deposited on the previously deposited layers. These thermal cycles affect the microstructure formation and mechanical properties of the deposited layers. Understanding the phenomena of heat transfer, liquid metal flow, cooling rates and other solidification parameters are important for controlling the microstructure of the deposited layer [5]. The highly localized heating and repeated thermal cycles that are part of this 
process induce complicated microstructure distributions in the part. The residual stresses resulting from the cyclic thermal expansions and contractions cause distortion in the component, which can adversely impact overall part quality [6].

Generally, part orientation was studied concerning building direction and angle of part orientation on the building platform. The shrinkage, internal stress, residual stress, distortion, surface roughness and manufacturability of the parts were investigated [7-9]. However, the effect of orientation distance (space between samples) has not been studied comprehensively. It is considered that the distances between samples are important parameters. The distance between samples can affect temperature distribution, maximum temperatures and failures on the samples. Understanding the effects of positioning distance between parts, experimental and theoretical models need to contain microscale melting analysis for whole manufacturing. A 3D thermal-mechanical model for the selective laser melting process was proposed for this purpose in the literature. The melting, volume shrinkage, vaporization and cooling processes were considered while the temperature and residual stress fields were examined based on the multi-layer model [10].

A transient thermal finite element model of a SLM process for Ti6Al4V was developed using ANSYS for predicting the melt pool size and thermal history. The thermal results were remapped to the structural problem for the prediction of the induced residual stress of the parts [11]. Yet in another study, A roadmap is tried to be developed to mitigate the distortion during additive manufacturing using a strain parameter and a well-tested, three-dimensional, numerical heat transfer as well as a fluid flow model. The computed results expose the effects of both the key process variables such as power, scanning speed and important non-dimensional parameters such as Marangoni and Fourier numbers and non-dimensional peak temperature on thermal strain [12].

The temperature gradient is varied by the distance between samples. In the literature, three types of temperature aspects were indicated to investigate different part properties. Microscale thermal model was related to melting pool geometry and microstructures. Mesoscale and macroscale thermal models were related to part distortions and stress on samples [13, 14]. To understand the macroscale problems, macroscale thermal models should be examined. In the macroscale aspect, temperatures of samples were commonly observed below $250^{\circ} \mathrm{C}$. In the literature, manufacturing parameters induced temperatures and the manufacturing problems were stated in many articles. In addition, some single part manufacturing cases were studied to ascertain relations among temperatures, residual stresses and strains. In this study, the cases of multiple-sample manufacturing at the same time were studied. Distances between samples were the key parameter to examine the effect of distance between samples on temperatures, strains and stresses. The optimum range of distance between samples was identified.

\section{MATERIALS AND METHODS}

Netfabb Ultimate Simulation 2019 software was used for simulating manufacturing processes and the manufacturing of Ti6Al4V specimens was carried out by EOS M280 DMLS. Ti6Al4V powder material was preferred in the study. Part density is $4.41 \mathrm{~g} / \mathrm{cm}^{3}$, the ultimate tensile strength is 1290 $\mathrm{MPa}$, elongation at break is $8-12 \%$ and also Vickers hardness value is $320 \mathrm{HV}$ [15]. Processing parameters were defined to get the most suitable mechanical properties obtained by the experiments. Manufacturing parameters are defined as $190 \mathrm{~W}$ of laser power, $1150 \mathrm{of} \mathrm{mm} / \mathrm{s}$ scanning speed, $0.1 \mathrm{~mm}$ of hatching distance and $3 \times 10^{-2} \mathrm{~mm}$ of layer thickness. The cooling rate of the samples was defined as $5.5 \times 10^{6}{ }^{\circ} \mathrm{C} / \mathrm{s}$. The building platform was sized as $250 \times 250 \times 25 \mathrm{~mm}$, while mesh size was chosen as 1 $\mathrm{mm}$. Even though the mesh size has been pre-defined, the software could change the mesh size in necessary areas to achieve precise analysis. Suitable geometry for the specimens was selected as a square prism. Dimensions of samples were 40x40x25 mm. 9 parts were located on the building platform at the same time for manufacturing analysis. The analysis was carried out with different distances $(1,5,10,12.5,15,20,25,27.5,30,45 \mathrm{~mm})$, but each time the distance between specimens was kept equal. The orientation of the samples was presented in Figure 1. Analysis of manufacturing processes was completed to observe temperatures, residual stresses and dimensional distortions. Then all the results were examined to understand the relations between the manufacturing properties and the orientation distances. 


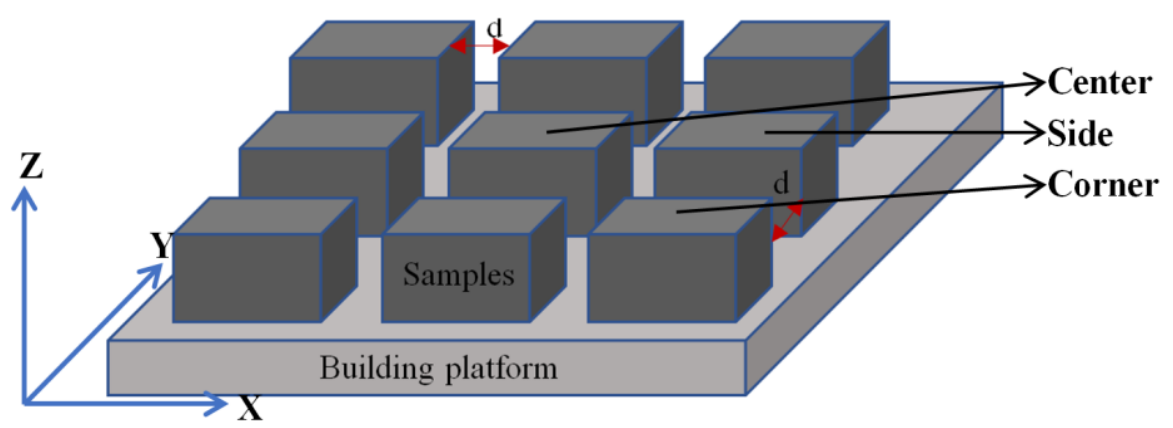

Figure 1.Orientation of samples

In addition to results taken by FEA, the mathematical model was generated to predict the plastic strain value of samples at the end of the manufacturing processes. The model consisted of temperature values, Cauchy stresses and distance between samples. Automatic Problem Solver (APS) software was used for deriving the equation of the plastic strain. The software was based on the genetic expressional programming language (GEP). Programming parameters were defined as 10 data, 2 genes, 5 gene heads, 80 chromosomes, and a minimum of 230000 generations of derivation. Generations pursued until $\mathrm{R}^{2}$ (regression) exceeded 0.9 .

The manufacturing time of all cases was the same. Total volume and the maximum height of the samples were constant for all cases as well. Thus the only the changed parameter was the distance between samples. Differences in the mechanical properties of samples were related to temperature values and distribution on the samples and building platform. The temperature changes were related to the heat transfer behaviors of samples during manufacturing. Basically, 3 main heat transfer mechanisms influenced the temperature gradients. These were conduction between the loose powder and the building platform, convection and radiation in the building chamber. Temperature gradients were affected by heat accumulations and heat transfers. Heat accumulations occurred due to the laser beam. Also, mass $(m)$ and specific heat capacity $\left(\mathrm{C}_{\mathrm{p}}\right)$ were important factors. Equation of heat $(\mathrm{q})$ is known as [16]:

$$
\mathrm{dq}=\mathrm{m} \cdot \mathrm{Cp} \cdot \mathrm{dT}
$$

The laser heat flux input $\left(\mathrm{q}_{\mathrm{i}}(\mathrm{t})\right)$ was represented by a Gaussian heat source expressed depending on laser power $(\mathrm{P})$, absorptivity $(\alpha)$ in equation 2 [17].

$$
q_{i}(t)=\frac{2 \alpha P}{\pi r^{2}} e^{\left(-2 \frac{\left(x_{i}-x_{\text {spot }}(t)\right)^{2}+\left(y_{i}-y_{\text {spot }}(t)\right)^{2}}{r^{2}}\right)}
$$

Heat transfer mechanisms could be expressed as conduction convection and radiation from the sample to outer areas. Each mechanism was identified by different equations. Conduction equation should contain the conduction coefficient (k): The equation of conduction was known as:

$$
\mathrm{dq}=\frac{\mathrm{kA}\left(\mathrm{T}_{\text {hot }}-\mathrm{T}_{\text {cold }}\right) \mathrm{t}}{\mathrm{d}}
$$

The transient thermal model was governed by 3D Fourier heat conduction equations, as described in equation 4 [18].

$$
\left(\frac{\rho \mathrm{C}_{\mathrm{p}}}{\mathrm{k}}\right) \frac{\partial \mathrm{T}}{\partial \mathrm{t}}=\frac{\partial^{2} \mathrm{~T}}{\partial \mathrm{x}^{2}}+\frac{\partial^{2} \mathrm{~T}}{\partial \mathrm{y}^{2}}+\frac{\partial^{2} \mathrm{~T}}{\partial \mathrm{z}^{2}}
$$

The sides of the part are given a Neumann zero heat flux boundary condition because heat loss to the loose powder bed on the sides of the part was assumed negligible. $C_{P}$ is specific heat capacity in 
$(\mathrm{J} / \mathrm{kgK}), \mathrm{k}$ is thermal conductivity in $(\mathrm{W} / \mathrm{mK}), \mathrm{r}$ is bulk density in $\left(\mathrm{kg} / \mathrm{m}^{3}\right)$ and $\mathrm{h}$ is heat transfer coefficient in $\left(\mathrm{W} / \mathrm{m}^{2} . \mathrm{K}\right)$.

$$
-\left.\mathrm{k} \frac{\partial \mathrm{T}}{\partial \mathrm{z}}\right|_{\mathrm{z}=\text { layer height }}=\mathrm{h}_{\mathrm{c}}\left(\mathrm{T}_{\mathrm{s}}-\mathrm{T}_{\mathrm{ch}}\right)+\mathrm{h}_{\mathrm{r}}\left(\mathrm{T}_{\mathrm{s}}-\mathrm{T}_{\mathrm{ch}}\right)
$$

The convection equation should contain convection coefficient $\left(\mathrm{H}_{\mathrm{c}}\right)$ and heat transfer area $(\mathrm{A})$. The equation of conduction is known as:

$$
\mathrm{dq}=\mathrm{H}_{\mathrm{c}} \mathrm{A}\left(\mathrm{T}_{\text {hot }}-\mathrm{T}_{\text {cold }}\right)
$$

Radiation equation should contain radiation coefficient $(\sigma)$. The equation of conduction is known as:

$$
\mathrm{dq}=\sigma\left(\mathrm{T}_{\text {hot }}^{4}-\mathrm{T}_{\text {cold }}^{4}\right) \mathrm{A}
$$

To find temperature value, these equations have to be identified in the finite element analysis software. The stress distribution was determined in the static structural model using the following equations.

$$
\begin{gathered}
\left\{\begin{array}{l}
\varepsilon_{x} \\
\varepsilon_{y} \\
\varepsilon_{z}
\end{array}\right\}=\frac{1}{E}\left[\begin{array}{ccc}
1 & -v & -v \\
-v & 1 & -v \\
-v & -v & 1
\end{array}\right]\left\{\begin{array}{l}
\sigma_{x} \\
\sigma_{y} \\
\sigma_{z}
\end{array}\right\}+\left[\begin{array}{ccc}
1 & 0 & 0 \\
0 & 1 & 0 \\
0 & 0 & 1
\end{array}\right]\left(\begin{array}{l}
\sigma_{x} \\
\sigma_{y} \\
\sigma_{z}
\end{array}\right\}+a\left(T_{s}-T_{r e f}\right) \\
\gamma_{x y}=\frac{T_{x y}}{2 G}+\gamma_{x y}{ }^{P} ; \gamma_{x y}=\frac{T_{x z}}{2 G}+\gamma_{x z}{ }^{P} ; \gamma_{x y}=\frac{T_{y z}}{2 G}+\gamma_{y z}{ }^{P}
\end{gathered}
$$

$\varepsilon$ is the normal strain, $\mathrm{G}$ is the shear modulus, $\sigma$ is the normal stress in (MPa), $\gamma$ is the shear stress in (MPa), $\mathrm{E}$ is the modulus of elasticity in (MPa), $\mathrm{G}$ is the modulus of rigidity in (MPa), and $v$ is the Poisson's ratio. P represents plastic deformation. Figure 2 showed the fundamental mechanism of heat transfers from start to end of the processing of a single track.

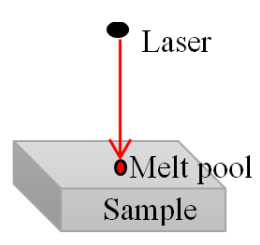

1) Laser started processing

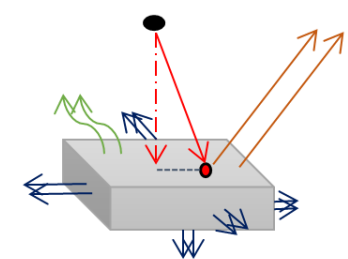

3) After some period of melting

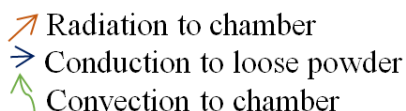

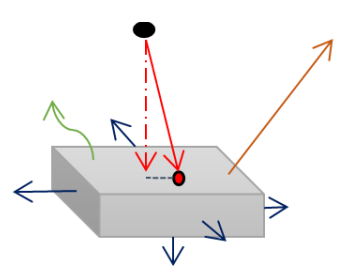

2) After a short period of melting

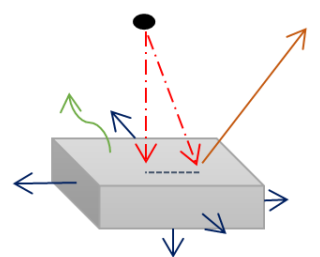

4) At the end of melting

$\downarrow$ Previous laser beam

$\vee$ Current laser beam

--- Melt pool track

Figure 2. Heat transfer mechanism of the single part L-PBF manufacturing process 
There were generally many samples were positioned on the building platform at the same time for applications in the literature. So, it was an obligation to understand the heat transfer mechanism during multiple parts manufacturing on the same platform and time. The processing of two samples was presented to indicate heat transfers in Figure 3.
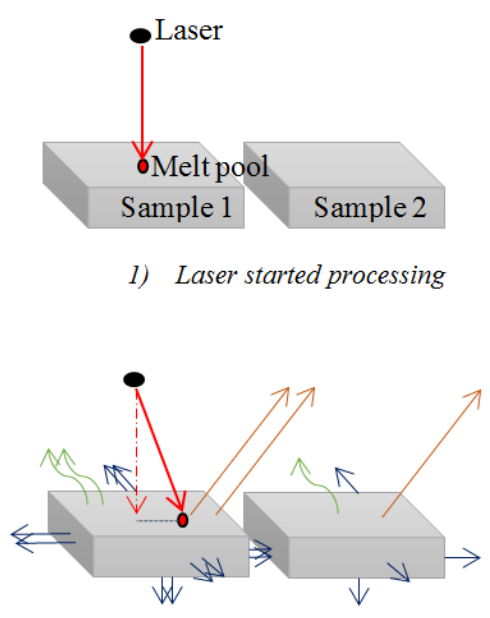

3) After some period of melting

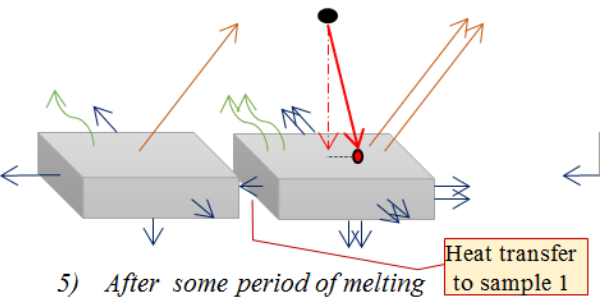

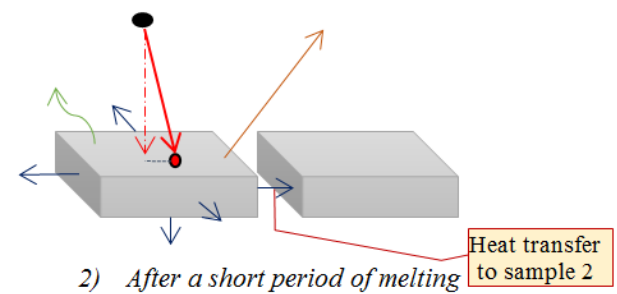

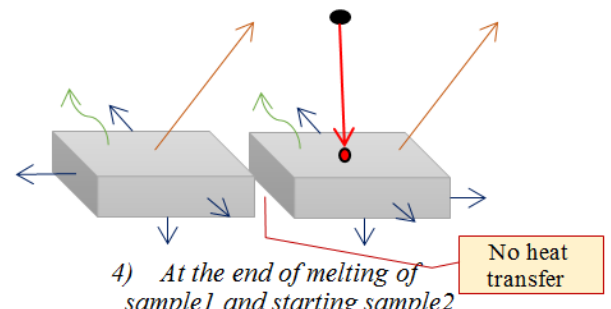

sample1 and starting sample 2

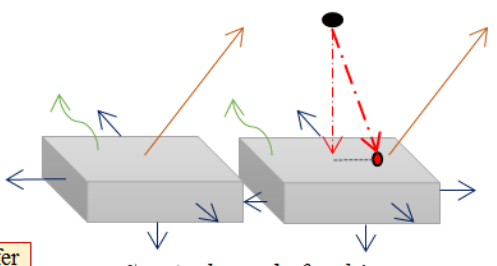

6) At the end of melting

$$
\begin{array}{ll}
\nearrow \text { Radiation to chamber } & \downarrow \text { Previous laser beam } \\
\rightarrow \text { Conduction to loose powder } & \downarrow \text { Current laser beam } \\
\widehat{\uparrow} \text { Convection to chamber } & - \text { Melt pool track }
\end{array}
$$

Figure 3. Heat transfer mechanism of double part L-PBF manufacturing process

10 different positioning distances of samples were defined to reach optimum values of equivalent plastic strain values. Strain values were measured after the manufacturing completed. The maximum values of strain values were considered. In the study, the residual stress values that were obtained by the finite element analysis software were verified for the 10x10x10 mm of cubic sample. Material and manufacturing parameters were set according to original experimental parameters. The highest residual stresses were observed by the XRD residual stress measurement device on the outer surface of the sample. Similarly, the highest residual stresses were observed on the outer surface of the sample by the software. Temperature values were recorded by a thermal camera (Optris PI 160). Also, dimensional tolerances were measured by a Coordinate Measurement Machine (CMM). Then, all the results were determined by comparing experimental and finite element analysis. The finite element analysis of the manufacturing cases was carried out by the Netfabb Simulation ${ }^{\circledR}$ software. Simulations were driven according to a well-organized work plan. The work plan is shown in Figure 4. 


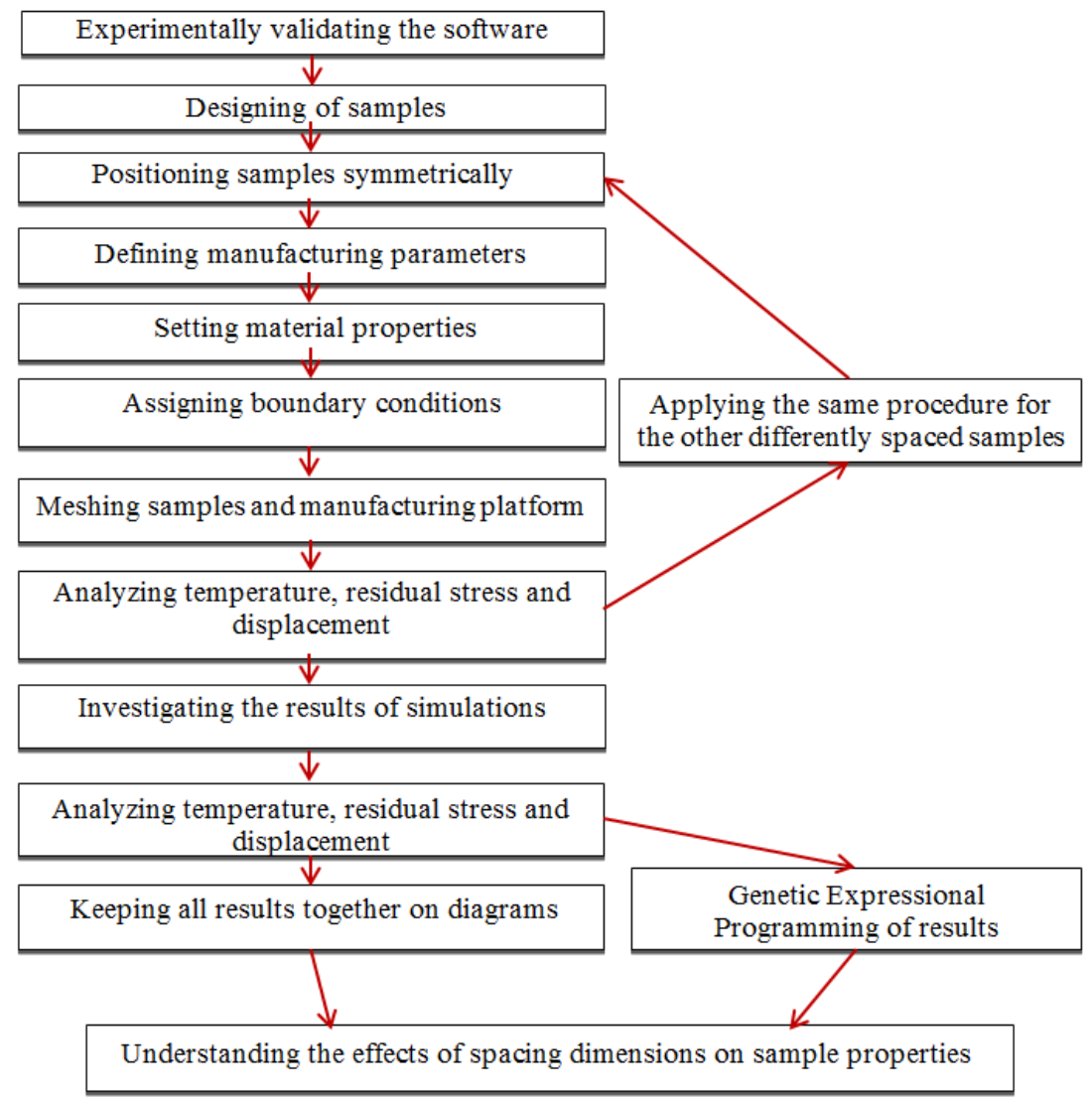

Fig.4.The workflow of the study

\section{RESULTS AND DISCUSSION}

The simulation software was experimentally tested before the main FEA analysis. The software was capable to analyze the manufacturing temperatures, displacements and residual stresses on the samples. To test the software, a single cubic sample was manufactured. Temperature gradients were observed during manufacturing. Temperature values through manufacturing were showed in Figure 5. Differences in temperature values were calculated as $\% 8$.

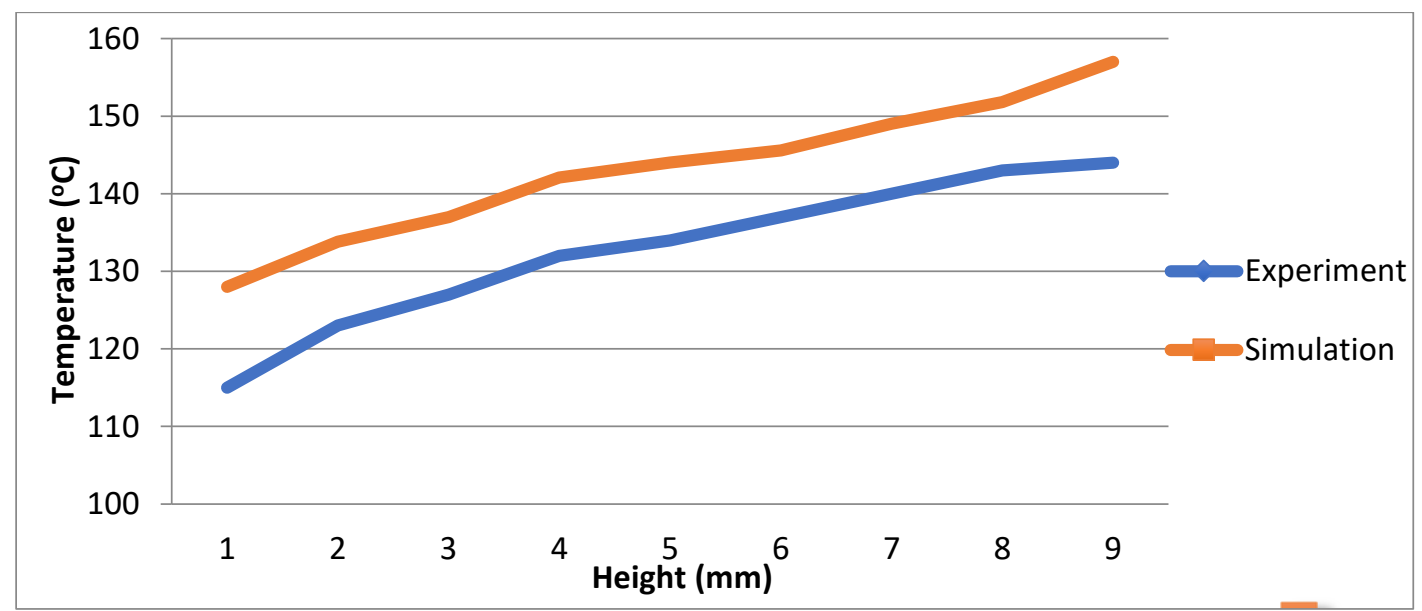

Figure 5. The maximum temperature values of the manufacturing

The highest residual stresses were observed as 330MPa by XRD residual stress measurement device on the center point of the top surface of the sample. Samples were cut from the building platform for testing by the XRD device. But also, the highest residual stresses were observed as $370 \mathrm{MPa}$ by the software on the outer surface of the sample. Then, it was determined that the FEA software gives accurate results with $12 \%$ differences. Also, displacement on the sample was measured by the CMM 
device and analyzed by the software. Displacement values were presented in Table1. Differences between experimental and simulation results of displacements were calculated as $11 \%$ of maximum.

Table1. The maximum displacement values of the manufacturing

\begin{tabular}{ccc}
\hline Heights $(\mathrm{mm})$ & Experiment & Simulation \\
\hline 3 & 0,175 & 0,155 \\
9 & 0,225 & 0,223 \\
\hline
\end{tabular}

After the validation of the software, simulations of the manufacturing processes were driven. One of the important results of the simulations was defining critical areas of samples during manufacturing. The critical areas of samples were shown in Figure 6. As can be seen in figure6, the contact area of the building platform and the samples have reached the highest value of equivalent plastic strain. Corners contained critical zones. The equivalent plastic strain was found as maximum of 0.117 .

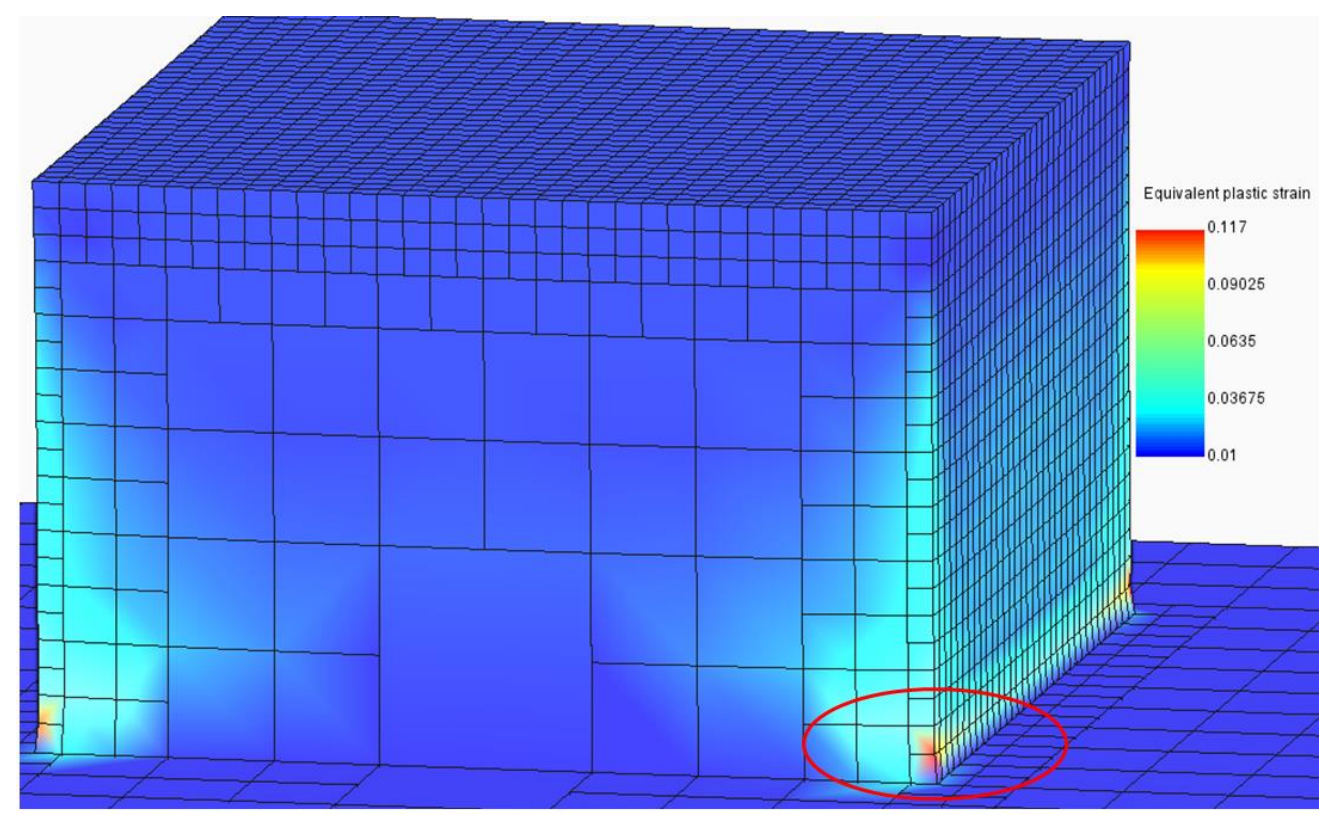

Figure 6. Critical zone utilizing Equivalent plastic strain

The first attempt was analyzing the temperature gradient during manufacturing for $1 \mathrm{~mm}$ and $45 \mathrm{~mm}$ spaced samples. Temperature was changed during manufacturing for both cases and the temperature increased until $4 \mathrm{~mm}$ heights. However, the temperature values were started to decrease after $6 \mathrm{~mm}$ heights. Temperature changing rate was related to the spacing distance of samples and it was higher on the closer samples than the further samples. Temperature values of $1 \mathrm{~mm}$ and $45 \mathrm{~mm}$ spaced samples were showed in Figure 7. 


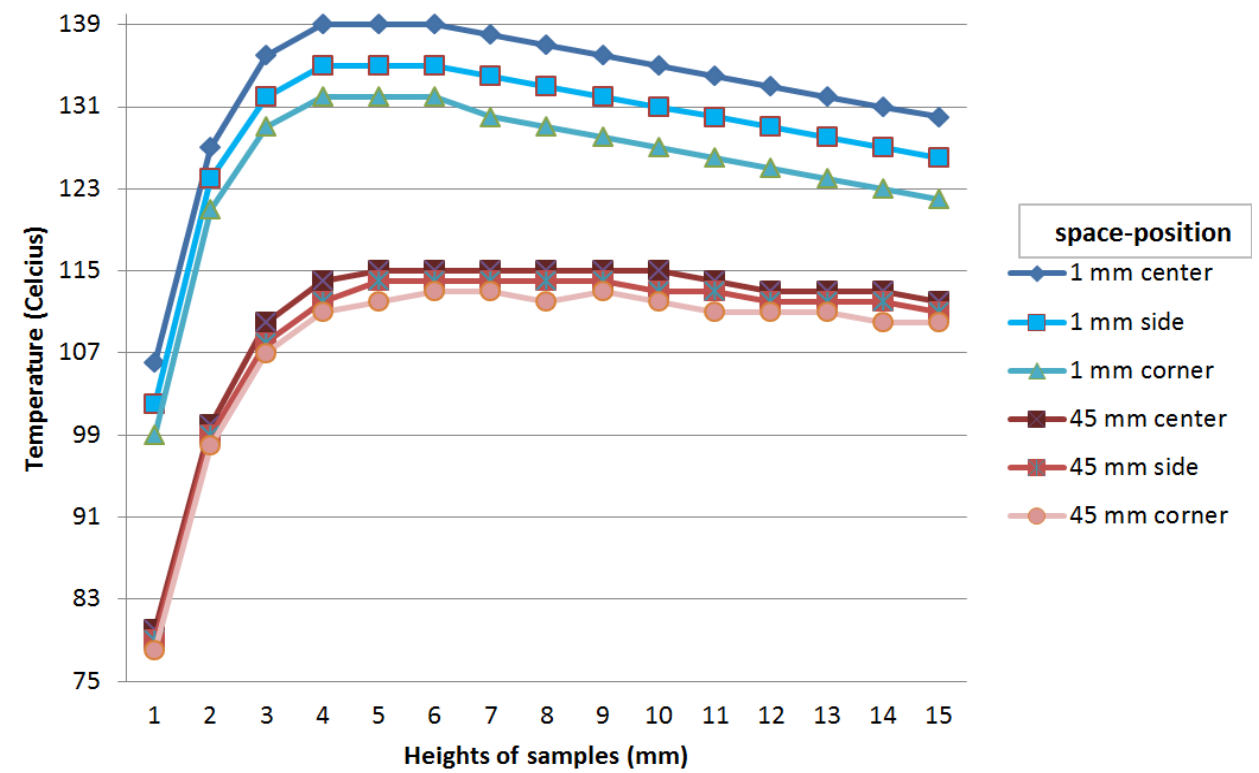

Figure 7. Temperatures of $1 \mathrm{~mm}$ and $45 \mathrm{~mm}$ samples during manufacturing

Equivalent plastic strain values were measured on the samples manufactured in ten different cases. In each case, samples which were located on the corner showed critical values of equivalent plastic strain value. The maximum equivalent plastic strain values were shown in Figure 8. Up to $10 \mathrm{~mm}$ spaced samples, equivalent strain values were increased. Equivalent strain values dramatically decreased after $10 \mathrm{~mm}$ and then dramatically increased after $25 \mathrm{~mm}$ up to $27.5 \mathrm{~mm}$. Values were stable between $27.5 \mathrm{~mm}$ and $45 \mathrm{~mm}$.

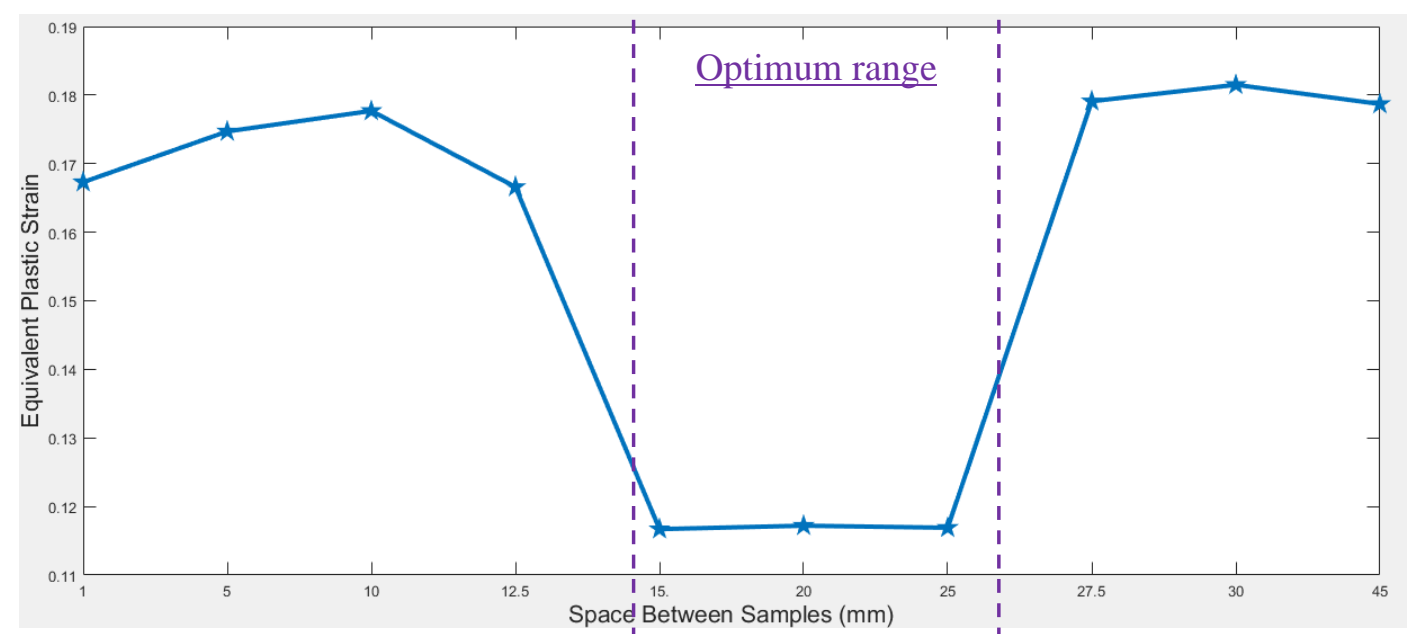

Figure 8. Simulation results with subject to distance of parts and Equivalent plastic strains

It was considered that these changes of equivalent strain values were related to the orientation properties of the samples and the manufacturing conditions. Maximum temperatures, temperature distribution and temperature differences have affected strain values of samples during manufacturing. Figure 9 shows the temperature values and distributions during manufacturing. The highly regular temperature distribution was seen on samples that were positioned with a small distance between the samples. As the distance between samples increased, temperature distribution became heterogeneous up to $27.5 \mathrm{~mm}$ space. Then temperature values were distributed regularly. This phenomenon was likely related to equivalent plastic strain values. 


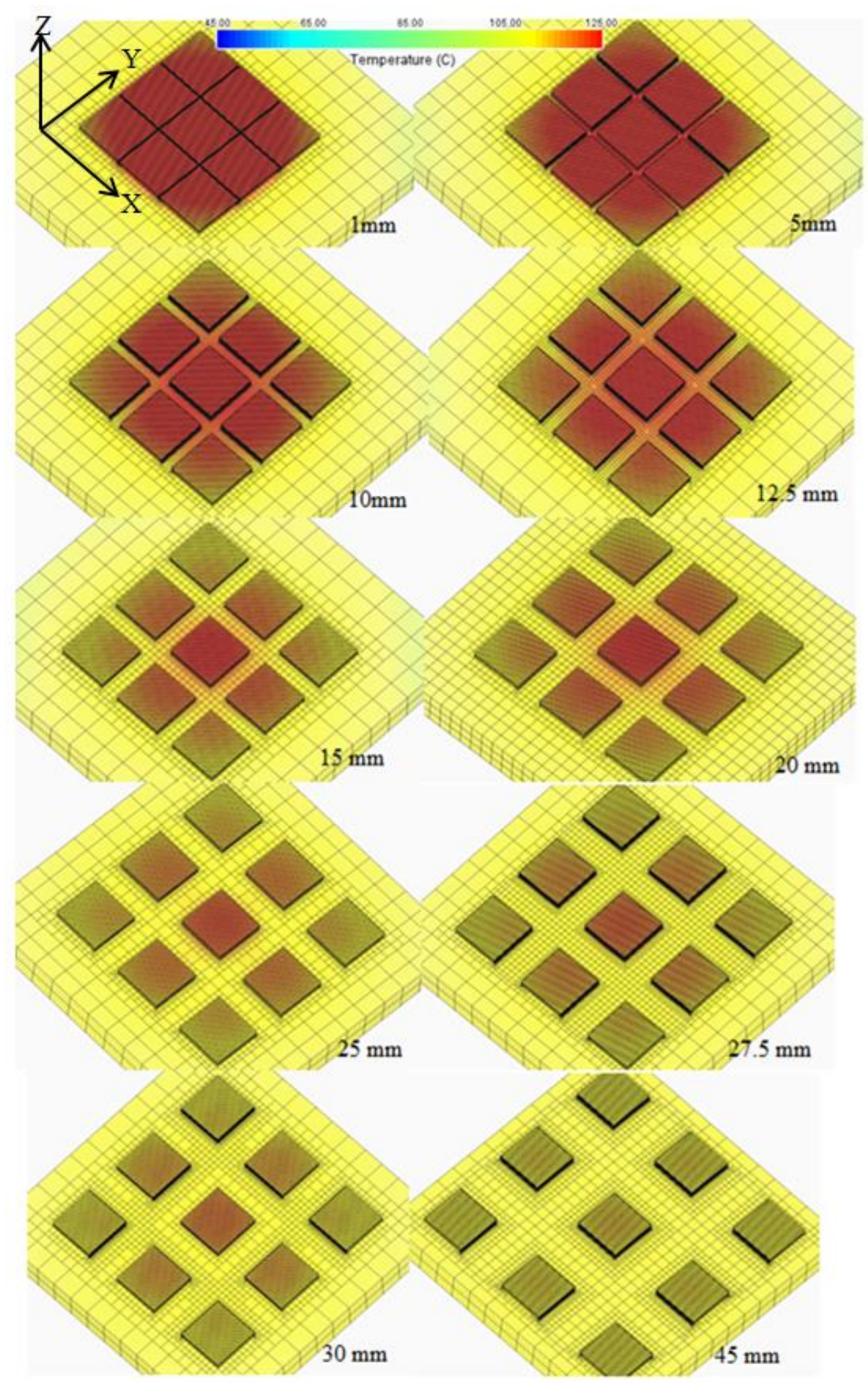

Figure 9. Temperature distribution of different spaced samples at $5 \mathrm{~mm}$ heights

In addition to the temperature distribution analysis of ten different manufacturing cases, the maximum temperature of the samples was measured. Results were shown in Figure 10. As seen in Figure 10, the maximum temperature values of samples decreased from $1 \mathrm{~mm}$ to $45 \mathrm{~mm}$ spaced samples. Heat transfer between samples had an important role in heat accumulation. As a result of the heat accumulation, temperature values were increased. Closer samples contained higher temperature values such as $1 \mathrm{~mm}$ and $5 \mathrm{~mm}$ spaced samples. 


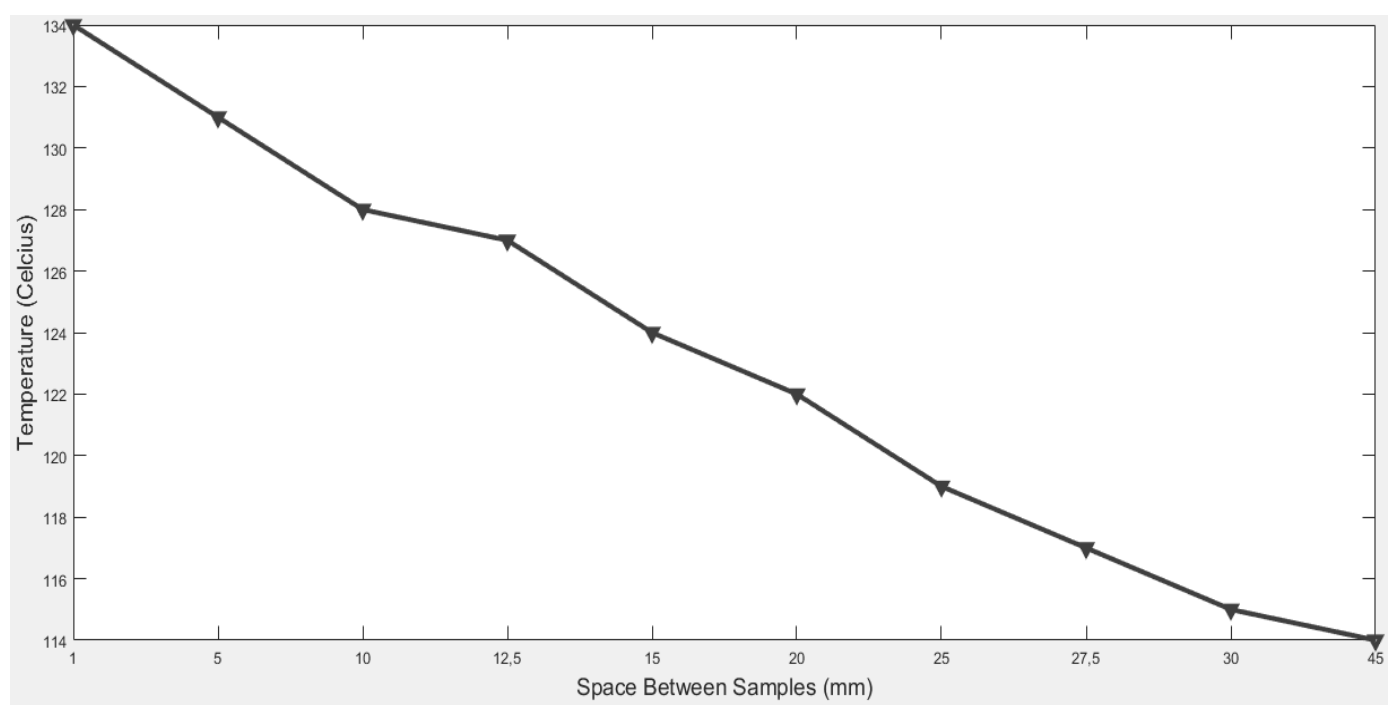

Figure 10. Simulation results with subject to distance of parts and Maximum temperature values

Temperature differences during manufacturing were also examined. In contrast to the results of maximum temperature analysis, temperature differences during manufacturing decreased from $1 \mathrm{~mm}$ to $45 \mathrm{~mm}$ space between samples. These temperature changes were related to the orientation of samples. Distantly spaced samples contained higher temperature differences values such as samples with $30 \mathrm{~mm}$ and $45 \mathrm{~mm}$ space wherefore heat transferred easily to loose powder and manufacturing chamber in distantly spaced samples. Although the top surface of the samples reached high temperatures, the bottom areas of the samples still stayed at low temperatures. However, the less spaced samples were not easily transferred heat to outer zones. Temperature differences during manufacturing were showed in Figure 11.

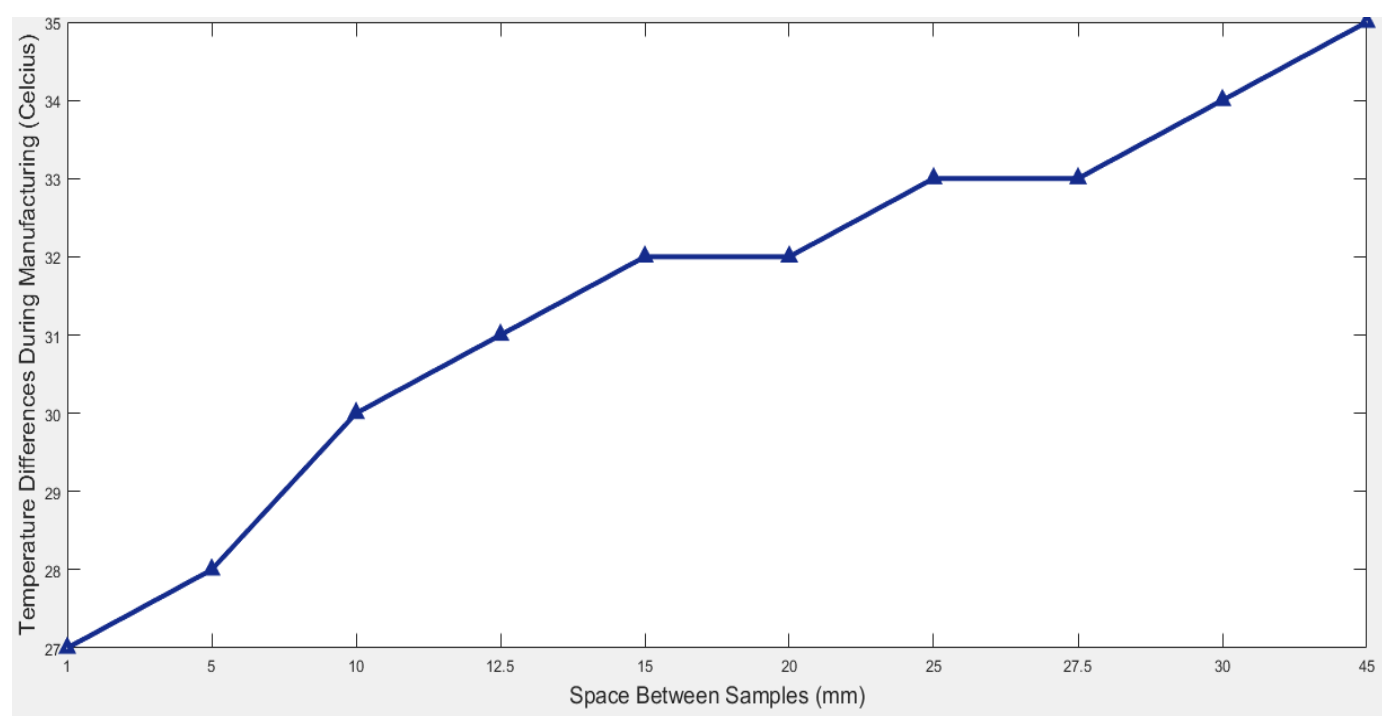

Figure 11. Simulation results with subject to space between samples and temperature differences

To understand the internal/residual stresses of samples, continuum mechanics is one of the most effective properties. Cauchy stress, also known as true mechanical stress, is defined as a force. The force was known as stress effects inside the area of a surface element. The material on one side of a surface element pushes, pulls or exerts force by different kinds of the material on the other side. Cauchy stresses completely define the state of stress at a point inside a material in the deformed state, placement, or configuration. For this purpose, Cauchy stress elements were analyzed. 6 Cauchy stress elements were investigated as $\sigma_{\mathrm{XX}}, \sigma_{\mathrm{YY}}, \sigma_{\mathrm{ZZ}}, \sigma_{\mathrm{XY}}, \sigma_{\mathrm{XZ}}$ and $\sigma_{\mathrm{YZ}}$. At the critical region of samples, $\sigma_{\mathrm{XX}}$ and $\sigma_{\mathrm{YY}}$ were observed as the same. In addition, $\sigma_{\mathrm{XZ}}$ and $\sigma_{\mathrm{YZ}}$ were observed as the same Figure 12 showed that Cauchy stress values related to the distance between samples at the critical zones [19, 20]. 


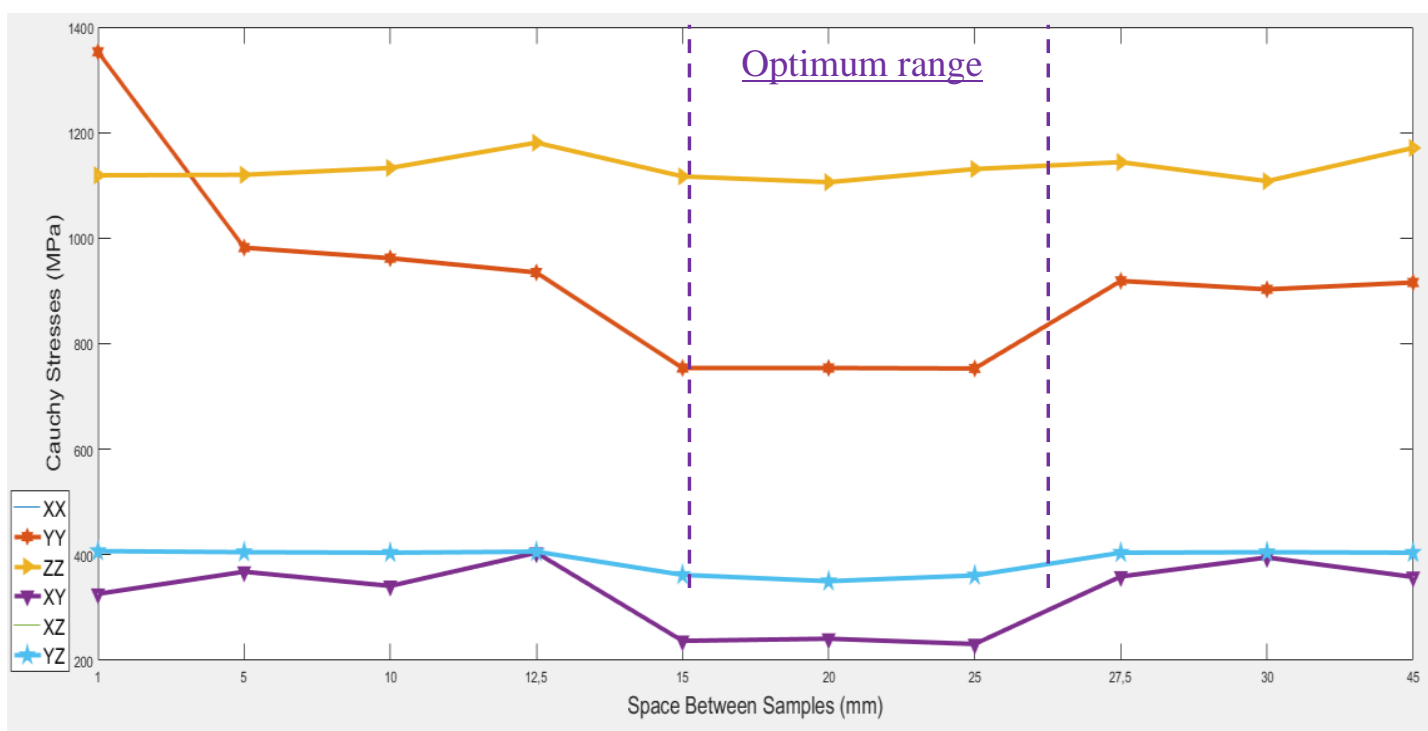

Figure 12. Simulation results with subject to distance of samples and Cauchy Stresses

Obviously, drawing curves of $\sigma_{\mathrm{XX}}, \sigma_{\mathrm{YY}}$ and $\sigma_{\mathrm{XY}}$ elements were quite similar to equivalent plastic strain curve. So it was thought that there was a relation between equivalent strain and Cauchy stresses. After all results and assumptions of analysis, a mathematical model was tried to be achieved. The mathematical model was generated by using APS software that is based on GEP. There were some abbreviations as "d" distance between samples, " $\mathrm{T}_{\max }$ " maximum temperature of manufacturing cases, "T $\mathrm{T}_{\text {dif }}$ " temperature differences on samples, " $\sigma_{\mathrm{XY}}$ " $\mathrm{XY}$ element of Cauchy stress and " $\delta_{\text {eq }}$ " equivalent strain.

$$
\delta_{\text {eq }}=\left(\frac{\sqrt{\sigma_{X Y}}}{\log d+T_{\max }}\right)+\left(\frac{\sin \left(\frac{\sigma_{X Y}-T_{\max }}{T_{\mathrm{dif}}}\right)}{T_{\mathrm{dif}}}\right)
$$

The $\mathrm{R}^{2}$ value of the model was found as 0.93 . The equation of the equivalent strain value depends on the sample that we have chosen. Probably, the model can be developed through the geometry of samples.

According to the results of the FEA analysis, both residual (Cauchy stress) stresses and equivalent plastic strain values were low between $15-25 \mathrm{~mm}$ positioning spaces. This range was an optimum area. Heat transfers and the models were considered together to understand the basis of this situation. Two main cases were important in this phenomenon. Both of them were related to the distance between samples. In the first case, far spacing was led samples to transfer their inner heats to loose powders. Thereafter, the other samples were not affected significantly by the heat transfers. The heat was not accumulated inside the samples. Thus; the maximum temperature values were positively low. In the other case, close spacing was led to temperature gradients being homogenous. There was not a remarkable amount of unbalanced and excessive heat transfer to loose powders. This time, the heat was accumulated inside samples. The negative effects of heat accumulation and heterogeneous temperature gradients were decreased and optimized between the optimum spacing ranges. Results were improved with \%29 after defining the suitable spacing ranges.

\section{CONCLUSIONS}

In this study, finite element analysis of 9 samples was executed with 10 different distances. Temperature values, distributions, Cauchy stresses and equivalent strain values were evaluated. Significant conclusions were given below.

- As the distance between samples was increased, the temperature distribution (temperature differences on the same part) on the parts became heterogeneous. As the distance between the samples was decreased, maximum temperatures were increased as can be seen in Figures 10 and 11 . 
- A regular temperature distribution was observed on the samples positioned with a small distance. Temperature differences on the same part became almost stable between $15 \mathrm{~mm}$ and $27.5 \mathrm{~mm}$ distances as can be seen in Figures 10 and 11.

- The distance between the samples should not be more or less than the optimum value since Cauchy stresses and equivalent strain are expected to be at minimum. According to the results of the study, optimum values of orientation distance between samples were ranged between 15 $\mathrm{mm}$ to $25 \mathrm{~mm}$.

- The negative effects of heat accumulation and heterogeneous temperature gradients were decreased and optimized between the optimum spacing ranges. Results were improved with $\% 29$ after defining the suitable spacing ranges.

- Finally, different geometries and dimensions can be studied experimentally and theoretically in the future works.

\section{ACKNOWLEDGMENTS}

Authors are thankful to Autodesk for significant supports by supplying Netfabb Simulation Utility.

\section{REFERENCES}

1. Bikas, H., Stavropoulos, R., Chryssolouris, G., "Additive manufacturing methods and modelling approaches: a critical review”, Int J Adv Manuf Technol, Vol.83, Pages 389-405, 2016.

2. Priarone, P.C., Lunetto, V., Atzeni, E., Salmi, A., "Laser powder bed fusion (L-PBF) additive manufacturing: On the correlation between design choices and process sustainability", Procedia CIRP, Vol.78, Pages 85-90, 2018.

3. Singh, R., Davim, P., "Additive manufacturing: Application and innovations", CRC Press, Taylor-Francis Group, 2019.

4. Lee, Y. S., Zhang, W., "Mesoscopic simulation of heat transfer and fluid flow in laser powder bed additive manufacturing. In International Solid Free Form Fabrication Symposium”, Austin Pages 1154-1165, 2015.

5. Manvatkar, V., De, A., DebRoy, T., "Heat transfer and material flow during laser assisted multi-layer additive manufacturing”, Journal of Applied Physics, Vol.116, Pages 124905, 2014.

6. Yang, Y.P., Jamshidinia, M., Boulware, P., Kelly, S.M., "Prediction of microstructure, residual stress, and deformation in laser powder bed fusion process", Computational Mechanics, Vol.61, Pages 599-615, 2018.

7. Ning Y., Fuh J. Y. H., Wong Y. S., Loh H. T., "An intelligent parameter selection system for the direct metal laser sintering process”. Int. J. Prod. Res, Cilt 42, Sayı 1, Sayfa 183-199, 2004.

8. Yang C., Hao L., Hussein A., Young P., Huang J., Zhu W., "Microstructure and mechanical properties of aluminum alloy cellular lattice structures manufactured by direct metal laser sintering". Mater. Sci. Eng. A, Vol.628, Pages 238-246, 2015.

9. Poyraz, Ö., Kuşhan, M. C. "Investigation of the effect of different process parameters for laser additive manufacturing of metals." Journal of the Faculty of Engineering and Architecture of Gazi University, Vol. 33, Issue 2, Pages 729-742, 2018.

10. Li, Y., Zhou, K., Tan, P., Tor, S. B., Chua, C. K., Leong, K. F., "Modeling temperature and residual stress fields in selective laser melting", International Journal of Mechanical Sciences, Vol.136, Pages 24-35, 2018.

11. Park, H. S., Tran, N. H., Nguyen, D. S., "Development of a predictive system for SLM product quality". In IOP Conference Series: Materials Science and Engineering, Vol.227, Issue 1, Pages 012090, 2018.

12. Mukherjee, T., Manvatkar, V., De, A., \&DebRoy, T., "Mitigation of thermal distortion during additive manufacturing", Scriptamaterialia, Vol.127, Pages 79-83, 2017.

13. Yan Z, Liu W, Tang Z, Liu X, Zhang N, Li M, Zhang H., "Review on thermal analysis in laser-based additive manufacturing", Optics and Laser Technology, Vol.106, Pages 427-441, 2018. 
14. Li, C., Fu, C.H., Guo Y.B., Fang, F.Z., “A multiscale modeling approach for fast prediction of part distortion in selective laser melting”, Journal of Materials Processing Technology, Vol.229, Pages 703-712, 2016.

15. EOS GMBH, "Material data sheet - Flexline EOS Titanium Ti64", EOS GmbH - Electro Optical Systems, 2018.

16. Stout, R., Billings, P.D., "Accuracy and time resolution in thermal transient finite element analysis", Semiconductor P. E. O. N. ANSYS ${ }^{\text {TM }}$ users conference, 2002.

17. Olleak, A., Xi, Z., "Finite Element Modeling of the Selective Laser Melting Process for Ti-6Al-4V", Solid Freeform Fabrication 2018: Proceedings of the 29th Annual International, Pages 1710-1720, 2018.

18. Yakout, M., Elbestawi, M. A., Veldhuis, S. C., \& Nangle-Smith, S.,"Influence of thermal properties on residual stresses in SLM of aerospace alloys", Rapid Prototyping Journal, Vol.26, Issue 1, 2019.

19. Chen, Y., "The origin of the distinction between microscopic formulas for stress and Cauchy stress", Europhysics Letters, Vol.116, Issue 3, Pages 34003, 2016.

20. Cauchy stress tensors, https://wikipedia.org/wiki/Cauchy_stress_tensoren, Nov 15, 2019 